\title{
Kelola
}

\section{STRATEGI PENINGKATAN MUTU SEKOLAH BERDASARKAN ANALISIS SWOT DI SEKOLAH MENENGAH PERTAMA}

\author{
Edi Sujoko \\ Sekolah Tinggi Teologi Simpson \\ Kabupaten Semarang-Jawa Tengah \\ edisujoko@sttsimpson.ac.id
}

\begin{abstract}
This research was a research and development study. The purpose of this research are (1) Describe what factors are the strengths, weaknesses, opportunities and threats in improving the quality in SMPN1 Bawen;(2) Develop a strategy that needs to be done to improve the quality SMPN1 Bawen based on SWOT analysis. Data was collected through interviews, observation, study of document and focus group discussion (FGD). The results of the SWOT analysis is to improve the quality of schools stated position SMPN1 Bawen be in SO quadrant, which supports an aggressive strategy to support the growth of the school created a strategic plan that leverages the power to capture the opportunities that exist. Draft strategic aspects: inputs, processes, and outputs include: developing the ideal school environment, through programs $7 \mathrm{~K}$ ( Health, Order, Beauty, Shade, Security, Comfort, and Kinship ; Optimization of teacher professional development programs, and improve academic achievement and non- academic as optimal as possible.
\end{abstract}

Keywords : Schools quality, SWOT Analysis, Strategic Plan. 


\section{PENDAHULUAN}

Saat ini persaingan antar SMP tidak dapat dihindarkan. Tiap sekolah memiliki strategi sendiri untuk bersaing, hal tersebut sudah menjadi tuntutan yang harus dilakukan untuk memperbaiki mutu dan meningkatkan mutu pendidikan. SMP di Kabupaten Semarang dibagi menjadi 7 sub rayon, khususnya di subrayon 02 terdapat 17 SMP. Dari 17 SMP tersebut terdapat 6 sekolah negeri dan 11 sekolah swasta. Banyaknya SMP dalam lingkup sempit membuat persaingan semakin ketat. Hal ini menjadi masalah bagi SMP yang kalah bersaing di mana mereka pasti akan kesulitan untuk mendapatkan target peserta didik baru yang diharapkan. Namun, bagi sekolah yang siap dan mampu bersaing pasti akan mendapatkan target yang diharapkan, bahkan lebih.

Orang tua peserta didik biasanya melihat dan mengukur sebuah sekolah baik atau tidak dengan melihat prosentase kelulusan peserta didik, nilai rata-rata yang dicapai sekolah dan peringkat sekolah (Sumarni, 2011). Maka hal ini menjadikan masingmasing sekolah menengah pertama berlombalomba menyusun strategi untuk meningkatkan mutu sekolah dengan tujuan memiliki prosentase kelulusan tinggi, nilai rata-ratanya tinggi dan juga mendapatkan peringkat yang baik. Selain dalam bidang akademis sekolah juga berlomba-lomba untuk meningkatkan bidang non-akademis, contohnya: kegiatan ekstrakurikuler sekolah.

Keadaan tersebut juga dialami oleh SMP Negeri 1 Bawen, yang terletak di Jl. Soekarno-Hatta no. 54. Sekolah ini merupakan sekolah yang paling strategis dibandingkan dengan SMP yang lainnya di sub rayon 02 Kabupaten Semarang. Lokasinya terletak di pinggir jalan raya dan semua angkutan umum dapat menjangkau sekolah ini. Selain itu sekolah memiliki luas area yang luas untuk mengembangkan sekolah. Namun demikian masih kalah saing dengan sekolah lainnya dalam beberapa hal, salah satunya adalah prestasi akademis. Sebagai contoh, adalah peringkat ujian nasional dari tahun 2008 sampai sekarang sekolah ini belum pernah menjadi yang terbaik meskipun memiliki banyak keunggulan dari beberapa sisi. Berikut ini adalah data yang menunjukkan bahwa SMP Negeri 1 Bawen belum bisa mengoptimalkan potensi yang ada. Pada Tabel dibawahinidapat dilihat data prosentase kelulusan dan peringkat lulusan tahun 2008/2009 s.d. 2012/2013.

Tabel 1 Prosentase Kelulusan dan Peringkat SMPN 1 Bawen Tahun 2008/2009 s.d. 2012/2013

\begin{tabular}{|c|c|c|c|c|}
\hline TahunPelajaran & $\begin{array}{c}\text { Prosentasekel } \\
\text { ulusan }\end{array}$ & $\begin{array}{c}\text { Rata- } \\
\text { rata } \\
\text { Nilai }\end{array}$ & $\begin{array}{c}\text { Jumlah } \\
\text { yang } \\
\text { tidak } \\
\text { Lulus }\end{array}$ & $\begin{array}{c}\text { Peringkat } \\
\text { Sekolah }\end{array}$ \\
\hline $2008 / 2009$ & $100 \%$ & 7.09 & 0 & $\mathbf{3}$ \\
\hline $2009 / 2010$ & $89.02 \%$ & 6.63 & 29 & $\mathbf{3}$ \\
\hline $2010 / 2011$ & $100 \%$ & 7.02 & 0 & $\mathbf{3}$ \\
\hline $2011 / 2012$ & $100 \%$ & 7.10 & 0 & $\mathbf{2}$ \\
\hline $2012 / 2013$ & $99.60 \%$ & 6.50 & 1 & $\mathbf{2}$ \\
\hline
\end{tabular}

Sumber: Data Sekunder, diolah

Tahun 2008/2009 prosentase kelulusannya $100 \%$ dengan peringkat 3, sedangkan tahun 2009/2010 prosentase kelulusan turun drastis menjadi $89,02 \%$ dengan peringkat 3. Meskipun ada sekitar 29 84 anak yang tidak lulus, tetapi mereka mendapatkan kesempatan untuk mengulangnya dan akhirnya lulus $100 \%$. Ditahun 2012/2013 ada 1 peserta didik yang tidak lulus dan peringkat sekolah meningkat 
menjadi 2. Namun pada tahun tersebut tidak ada ujian ulang sehingga satu peserta didik yang tidak lulus harus diikutkan paket $\mathrm{C}$.

Dalam bidang non-akademis SMPN 1 Bawen juga belum menunjukkan prestasi yang memuaskan dari waktu ke waktu, meskipun ada beberapa cabang kegiatan ekstrakurikuler yang sudah memiliki prestasi yang cukup baik. Berikut ini data kegiatan non-akademis yang diselenggarakan sekolah beserta kejuaraan yang diperoleh.

Tabel 2 Prestasi Bidang Non - Akademis Tingkat Kecamatan, Kabupaten dan Propinsi

\begin{tabular}{|c|c|c|c|c|c|c|c|c|c|c|c|c|}
\hline \multirow{3}{*}{ Jenis Kegiatan } & \multicolumn{12}{|c|}{ Peringkat yang diperoleh } \\
\hline & \multicolumn{3}{|c|}{2011} & \multicolumn{3}{|c|}{2012} & \multicolumn{3}{|c|}{2013} & \multicolumn{3}{|c|}{2014} \\
\hline & ن & $\begin{array}{l}\dot{\tilde{\pi}} \\
\dot{v}\end{array}$ & $\frac{\dot{2}}{0}$ & $\begin{array}{c}\dot{0} \\
\ddot{v}\end{array}$ & $\begin{array}{l}\dot{\tilde{\Xi}} \\
\dot{\underline{y}}\end{array}$ & $\frac{\dot{2}}{2}$ & ن & $\begin{array}{l}\dot{\tilde{\sigma}} \\
\dot{v}\end{array}$ & $\frac{\dot{2}}{0}$ & ن & $\dot{\tilde{\mathscr{E}}}$ & $\frac{\dot{2}}{2}$ \\
\hline Pramuka & - & - & - & - & 2 & - & - & - & - & - & - & - \\
\hline PMR & - & - & - & - & - & - & - & - & - & - & - & - \\
\hline Band & - & 1 & - & - & 2 & - & - & 3 & - & - & 3 & - \\
\hline Vocal & - & - & - & - & - & - & - & 3 & - & - & - & - \\
\hline Seni Lukis & - & 1 & - & - & 1 & - & - & - & - & - & - & - \\
\hline Rebana & - & - & - & 1 & - & - & - & - & - & - & - & - \\
\hline Pildacil & - & - & - & - & - & - & 1 & 1 & - & - & 1 & - \\
\hline Pencak Silat & 1 & 1 & 1 & 1 & 1 & 1 & 1 & 1 & 1 & 1 & 1 & 1 \\
\hline Bola Voli & - & - & - & - & 2 & - & - & - & - & - & - & - \\
\hline Basket & - & - & - & - & - & - & - & 3 & - & - & - & - \\
\hline Sepak Bola- & - & 1 & - & - & 1 & - & - & 1 & - & - & 1 & 3 \\
\hline Bulutangkis & - & 2 & - & - & 2 & - & - & 2 & - & - & - & - \\
\hline Renang & - & - & - & - & - & - & - & - & - & - & - & - \\
\hline Jurnalistik & - & - & - & - & - & - & - & - & - & - & - & - \\
\hline
\end{tabular}

Sumber : Data Sekunder, diolah

Selama kurun waktu sekitar 4 tahun pencapaian bidang non-akademis SMPN 1 Bawen masih kurang memuaskan. Sekolah jarang mendapatkan nomor kejuaraan di tingkat kabupaten apalagi provinsi. Berdasarkan pengamatan dan wawancara dengan Kepala Sekolah SMPN 1 Bawen dan beberapa guru hal tersebut disebabkan kurang optimalnya pembimbing dalam melakukan pembimbingan serta masih rendahnya motivasi peserta didik dalam mengikuti kegiatan nonakademis tersebut.

Melihat data-data di atas, maka bisa dikatakan bahwa SMPN 1 Bawen perlu strategi alternatif untuk meningkatkan mutu pendidikan agar mampu bersaing. Guna meningkatkan mutu pendidikan ditentukan oleh aspek input, proses, dan output yang ada pada sekolah tersebut, dengan melakukan perbaikan secara berkesinambungan.

Manajemen strategis semakin penting arti dan manfaatnya apabila diingat bahwa lingkungan organisasi mengalami perubahan yang semakin cepat dan komplek, sehingga keberhasilan manajemen strategis ditentukan oleh para manajer atau pimpinannyadalam proses peningkatan mutu pendidikan secara berkesinambungan. Menurut Rindaningsih (2009) pengertian manajemen strategis adalah proses atau rangkaian kegiatan pengambilan keputusan yang bersifat mendasar dan menyeluruh, disertai penetapan cara 
pelaksanaannya, yang dibuat oleh manajemen puncak dan diimplementasikan oleh seluruh jajaran di dalam suatu organisasi, untuk mencapai tujuannya.

Hal penting selanjutnya guna mencapai mutu pendidikan yang optimal danber- kesinambungan adalah rencana strategis pendidikan. Dalam penelitian ini adalah rencana yang dilakukan oleh stakeholder sekolah dengan memperhatikan prinsip perbaikan hasil pendidikan, membawa perubahan yang lebih baik, prioritas kebutuhan, partisipasi, keterwakilan, realitas sesuai dengan hasil analisis SWOT, mendasarkan pada hasil review dan evaluasi, keterpaduan menyeluruh, transparan, dan keterkaitan serta kesepadanan secara vertikal dan horizontal dengan rencana-rencana lain.

Mutu pendidikan tidak hanya ditentukan oleh sekolah sebagai lembaga pengajaran tetapi juga disesuaikan dengan apa yang menjadi harapan dan pandangan masyarakat yang cenderung berkembang seiring dengan kemajuan jaman. Bertitik tolak pada kecenderungan ini penilaian masyarakat tentang mutu lulusan sekolahpun terus berkembang. Karena itu sekolah harus terusmenerus meningkatkan mutu lulusannya dengan menyesuaikan dengan perkembangan tuntutan masyarakat menuju pada mutu pendidikan yang dilandasi tolok ukur norma ideal (Sumarni, 2011).

Lewis dan Smith (dalam Tjiptono \& Diana, 2003) mengatakan bahwa pendekatan sistem terbuka menekankan kebutuhan kualitas pada ketiga tahap utama, yaitu akreditasi, proses transformasi, dan assessment. Akreditasi berkaitan dengan input, sedangkan assessment berkaitan dengan output. Input meliputi kemampuan dasar peserta didik, sumber daya pendanaan, fasilitas, dan program. Proses meliputi desain pembelajaran, metode pembelajaran, dan sistem analisis data. Sedangkan output adalah prestasi peserta didik dan pasca kelulusan.
Mutu tidak terjadi begitu saja, namun perlu suatu proses perencanaan. Mutu menjadi bagian penting dari strategi institusi dan harus didekati secara sistematis dengan menggunakan proses perencanaan strategis. Tanpa arahan jangka panjang yang jelas, sekolah sebagai sebuah institusi pendidikan tidak dapat merencanakan peningkatan mutu (Rozari, 2011). Oleh sebab itu rencana strategis peningkatan mutu mutlak dilakukan oleh institusi pendidikan untuk mempertahankan sekolah dari persaingan yang semakin ketat. Rencana strategis merupakan rencana komprehensif dengan melibatkan semua sumber dan kemampuan untuk meningkatkan kualitas proses belajar mengajar, mencapai sasaran sekolah, dan juga memenangkan persaingan yang ada.

Rencana strategis peningkatan mutu sekolah dalam implementasinya tidak lepas dari manajemen peningkatan mutu sekolah. Berkaitan dengan hal ini, Usman (2002) menyatakan bahwa manajemen peningkatan mutu memiliki prinsip (1) peningkatan mutu harus dijalankan di sekolah, (2) peningkatan mutu hanya dapat dilaksanakan dengan adanya kepemimpinan yang baik, (3) peningkatan mutu harus didasarkan pada data dan fakta baik bersifat kualitatif maupun kuantitatif, (4) peningkatan mutu harus memberdayakan dan melibatkan semua unsur yang ada di sekolah, (5) peningkatan mutu memiliki tujuan bahwa sekolah dapat memberikan kepuasan kepada peserta didik, orang tua dan masyarakat.

Dalam merumuskan rencana strategis untuk meningkatkan mutu sekolah diperlukan alat analisa. Adapun alat analisa yang sering digunakan adalah analisa SWOT. SWOT adalah singkatan dari Strengths, Weaknesses, Opportunities, dan Threats. Rangkuti (2009) menjelaskan Strengths adalah beberapa hal yang merupakan kelebihan dari sekolah yang bersangkutan. Weaknesses adalah komponenkomponen yang kurang menunjang 
keberhasilan penyelenggaraan pendidikan yang ingin dicapai sekolah. Opportunity adalah kemungkinan-kemungkinan yang dapat dicapai apabila potensi-potensi yang ada di sekolah mampu dikembangkan secara optimal.
Threats adalah kemungkinan yang mungkin terjadi atau pengaruh terhadap kesinambungan dan keberlanjutan kegiatan penyelenggaraan sekolah. Berikut ini adalah diagram analisis SWOT.

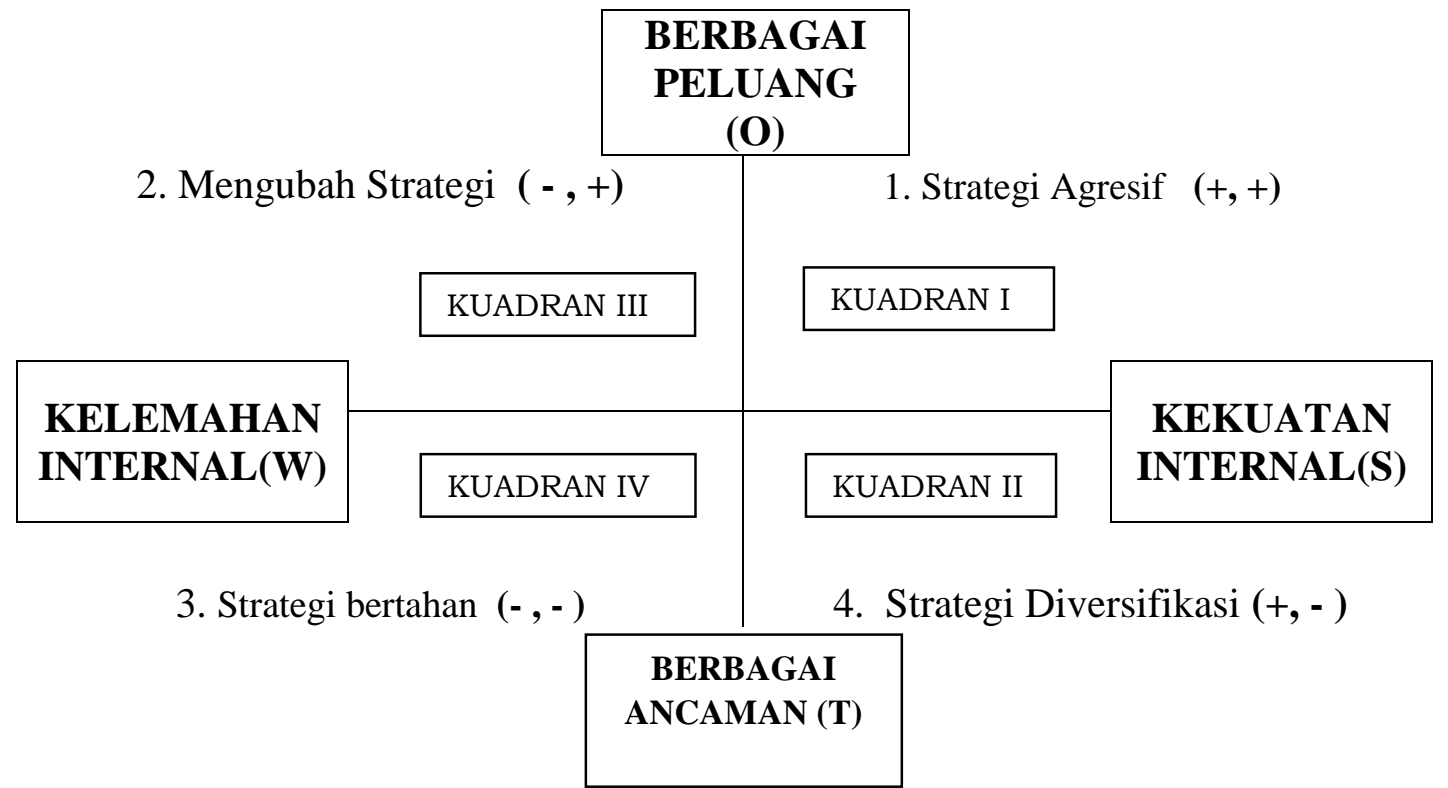

Sumber: Rangkuti, 2009

Gambar 1 Diagram Analisis SWOT

Berdasarkan latar belakang di atas maka rumusan masalah yang dapat diangkat dalam penelitian ini adalah sebagai berikut:

1. Apa saja yang menjadi faktor kekuatan, kelemahan, peluang dan ancaman dalam meningkatkan mutu di SMPN 1 Bawen?

2. Strategi apa saja yang perlu dilakukan untuk meningkatkan mutu SMPN 1 Bawen berdasarkan analisis SWOT?

Berdasarkan rumusan masalah di atas maka yang menjadi tujuan dalam penelitian ini adalah:

1. Mendeskripsikan faktor apa saja yang menjadi kekuatan, kelemahan, peluang dan ancaman dalam meningkatkan mutu di SMPN 1 Bawen;

2. Menyusun strategi yang perlu dilakukan untuk meningkatkan mutu SMPN 1 Bawen berdasarkan analisis SWOT.

\section{METODE PENELITIAN}

Desain yang digunakan untuk penelitian ini adalah desain penelitian pengembangan. Dalam penelitian ini dibatasi sampai menghasilkan produk saja yaitu sampai menghasilkan rencana strategis peningkatan mutu SMPN 1 Bawen. Penelitian dilakukan di SMPN 1 Bawen yang berlokasi di Jl. Soekarno - Hatta No. 54 Bawen. Penelitian berlangsung pada tanggal 1 Agustus 2014 sampai dengan 27 Agustus 2014. Data primer dari penelitian ini adalah data yang didapatkan secara langsung dari objek yang diteliti, diperoleh dari data pertama atau pihak yang dianggap paling tepat untuk memberikan informasi. Dalam penelitian ini data primer berupa faktor-faktor kekuatan, kelemahan, peluang, dan ancaman bagi peningkatan mutu sekolah di SMPN 1 Bawen. Subjek utama dalam penelitian ini adalah kepala sekolah, guru, staf, dan komite. 


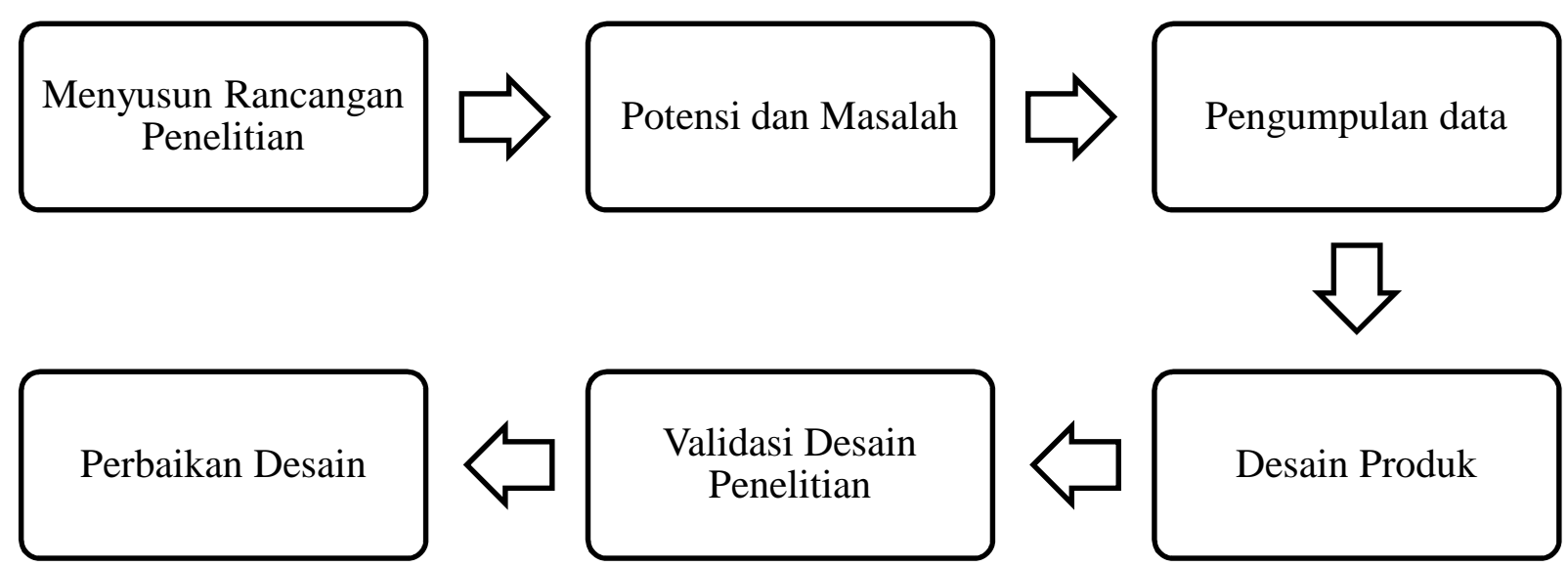

Gambar 2 Desain Penelitian

(Diadaptasi dari Sugiyono dan Arikunto)

Sedangkan data sekunder adalah data yang telah diolah lebih lanjut dan disajikan dengan baik oleh pengumpul data atau pihak lain. Dalam penelitian ini data sekunder diperoleh dari sumber tertulis melalui studi dokumentasi seperti profil sekolah, data guru, hasil kelulusan peserta didik, rencana strategis sekolah, prestasi akademik dan non-akademis, daftar inventaris, dan jumlah peserta didik. Metode pengumpulan data dari penelitian dapat dilihat melalui tabel sebagai berikut:

Tabel 3 Metode Pengumpulan Data

\begin{tabular}{|l|l|l|l|l|}
\hline No & \multicolumn{1}{|c|}{ Data } & \multicolumn{1}{|c|}{ Sumber Data } & \multicolumn{1}{|c|}{$\begin{array}{c}\text { Metode } \\
\text { Pengumpulan } \\
\text { Data }\end{array}$} & \multicolumn{1}{|c|}{ Instrumen } \\
\hline 1 & $\begin{array}{l}\text { Bagaimana rencana strategis } \\
\text { sekolah di-susun dan } \\
\text { dampaknya selama ini. }\end{array}$ & $\begin{array}{l}\text { Dokumen, kepala } \\
\text { sekolah, guru, staff, } \\
\text { dan komite sekolah }\end{array}$ & $\begin{array}{l}\text { Studi dokumen, dan } \\
\text { teknik wawancara }\end{array}$ & $\begin{array}{l}\text { Pedoman } \\
\text { wawancara }\end{array}$ \\
\hline 2 & $\begin{array}{l}\text { Kekuatan, kelemahan, } \\
\text { peluang, dan ancaman }\end{array}$ & $\begin{array}{l}\text { Kepala sekolah, } \\
\text { guru, staff, dan } \\
\text { komite sekolah }\end{array}$ & FGD & Pedoman FGD \\
\hline 3 & $\begin{array}{l}\text { Fasilitas sekolah, kegiatan } \\
\text { sekolah. }\end{array}$ & Bukti fisik & Observasi & Lembar obser-vasi \\
\hline
\end{tabular}

\section{HASIL DAN PEMBAHASAN}

\section{Hasil Analisis SWOT SMPN 1 Bawen}

a. Rencana Strategis Peningkatan Mutu Sekolah Aspek Input

Tabel 4 Skor Akhir IFAS dan EFAS Aspek Input

\begin{tabular}{|l|c|l|c|}
\hline \multicolumn{2}{|c|}{ IFAS } & \multicolumn{2}{c|}{ EFAS } \\
\hline Kategori & $\begin{array}{c}\text { Total } \\
\text { Skor }\end{array}$ & Kategori & $\begin{array}{c}\text { Total } \\
\text { Skor }\end{array}$ \\
\hline Kelematan (S) & 4,01 & Peluang (O) & 3,50 \\
\hline Total (S-W) & 3,00 & Ancaman $(\mathrm{T})$ & 2,70 \\
\hline
\end{tabular}

Dari hasil matrik IFAS dan EFAS diketahui skor akhir IFAS adalah 1,01 dan total skor akhir EFAS adalah $\mathbf{0 , 8 0}$. Hasil tersebut kemudian ditunjukkan melalui matrik SWOT di bawah ini: 


\section{Peluan}

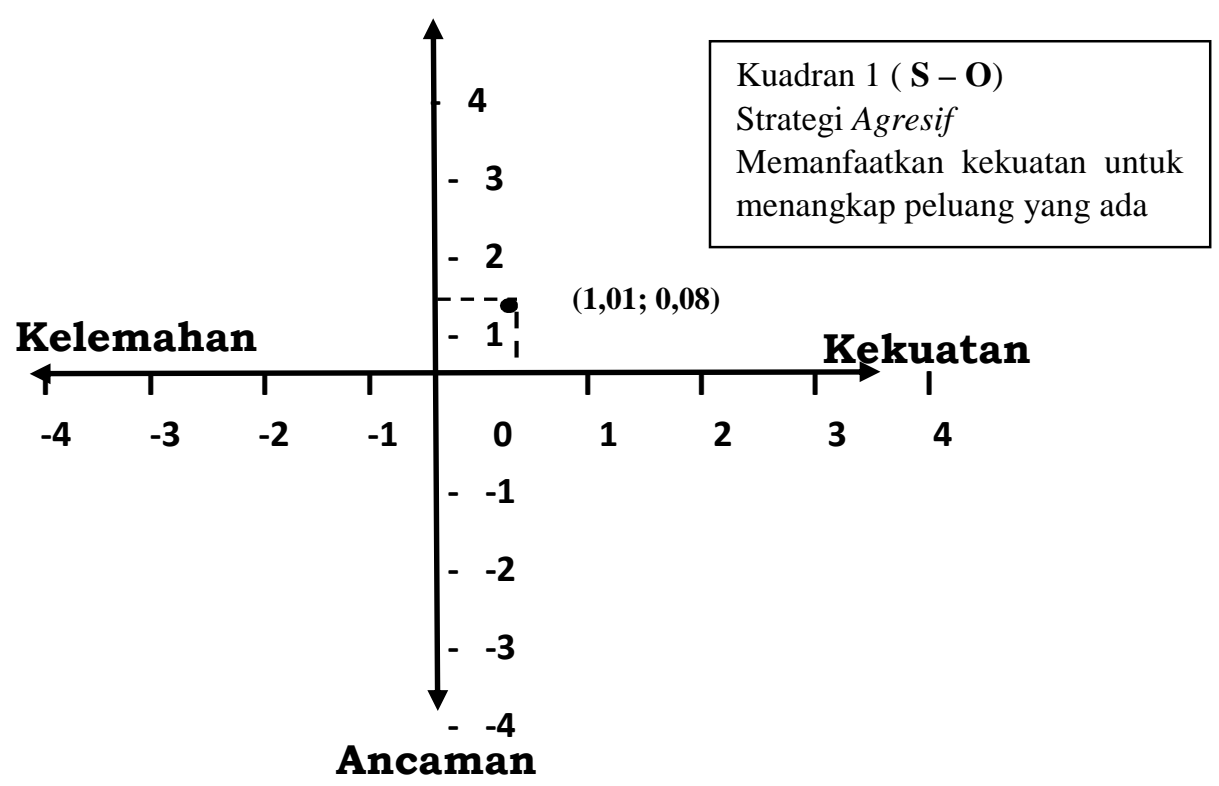

Gambar 3 Matrik SWOT Skor Akhir IFAS dan EFAS Aspek Input

Tabel 4 Rencana Strategis Berdasarkan Hasil Analisis SWOT

\begin{tabular}{|c|c|c|c|c|c|}
\hline \multirow[b]{2}{*}{ Faktor Internal } & \multicolumn{5}{|c|}{ Peluang } \\
\hline & 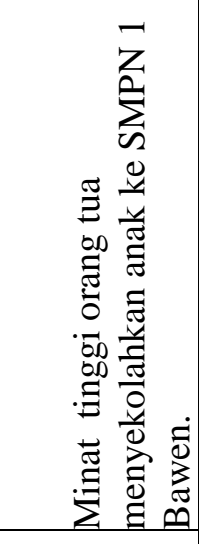 & 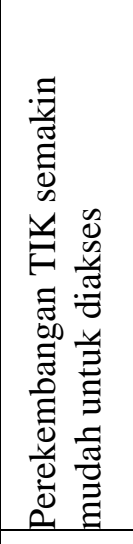 & 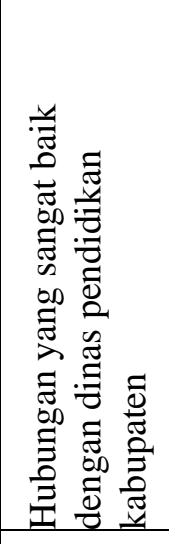 & 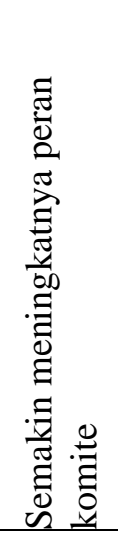 & 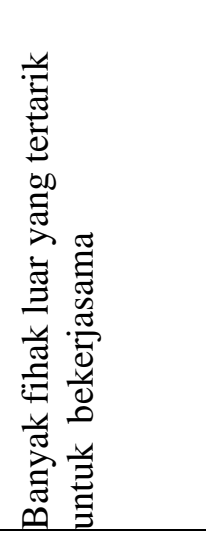 \\
\hline & 1 & 2 & 3 & 4 & 5 \\
\hline Kekuatan & \multicolumn{5}{|c|}{ Strategi S - O (Strength - Opportunity) } \\
\hline Lokasi sekolah sangat strategis & \multirow{7}{*}{\multicolumn{5}{|c|}{$\begin{array}{l}\text { 1. Mengembangkan lingkungan sekolah menuju komunitas belajar } \\
\text { yang ideal, yaitu melalui program } 7 \mathrm{~K} \text { (Kebersihan, Ketertiban, } \\
\text { Keindahan, Kerindangan, Keamanan, Kenyamanan, dan } \\
\text { Kekeluargaan). } \\
\text { 2. Membentuk klub-klub prestasi untuk mengembangkan potensi } \\
\text { peserta didik, baik dari sisi akademis ataupun non akademis. } \\
\text { 3. Memberdayakan tenaga pendidik dan kependidikan melalui } \\
\text { pelatihan-pelatihan intensif sehingga akan meningkatkan } \\
\text { kinerja. } \\
\text { 4. Pengembangan fasilitas sekolah berbasis TIK sebagai sarana } \\
\text { untuk belajar peserta didik. } \\
\text { 5. Dibentuk Tim Evaluasi program dan kegiatan sekolah secara } \\
\text { efektif dan efisien. }\end{array}$}} \\
\hline $98 \%$ guru berpendidikan $\mathrm{S} 1$ & & & & & \\
\hline Kamampuan dasar peserta didik baik & & & & & \\
\hline $\begin{array}{l}\text { Jumlah buku ajar untuk guru dan } \\
\text { peserta didik mencukupi }\end{array}$ & & & & & \\
\hline $\begin{array}{l}\text { Kemampuan manajemen kepala } \\
\text { sekolah cukup baik }\end{array}$ & & & & & \\
\hline $\begin{array}{l}\text { Dana untuk operasi sekolah } \\
\text { mencukupi }\end{array}$ & & & & & \\
\hline Fasilitas cukup lengkap & & & & & \\
\hline
\end{tabular}


Berdasarkan hasil analisis SWOT tersebut maka rencana strategis yang perlu dibuat sebagai upaya peningkatan mutu sekolah untuk aspek input di SMPN 1 Bawen adalah sebagai berikut: (1) Mengembangkan lingkungan sekolah menuju komunitas belajar yang ideal, yaitu melalui program $7 \mathrm{~K}$ (Kebersihan, Ketertiban, Keindahan, Kerindangan, Keamanan, Kenyamanan, dan Kekeluargaan); (2) Membentuk klub-klub prestasi untuk mengembangkan potensi peserta didik, baik dari sisi akademis ataupun non akademis; (3) Mengoptimalkan peran kepala sekolah dalam memberdayakan dan melatih kepemimpinan dan manajerial tenaga pendidik dan dan tenaga kependidikan;

Pengembangan fasilitas sekolah berbasis TIK sebagai sarana untuk belajar peserta didik; (5) Dibentuk Tim Evaluasi program dan kegiatan sekolah secara efektif dan efisien. b. Rencana Strategis Peningkatan Mutu Sekolah Aspek Proses

Setelah mengidentifikasi berbagai faktor kekuatan, kelemahan, peluang dan ancaman untuk aspek proses kemudian diberi bobot dan skor maka hasil perhitungan untuk total skor akhir adalah sebagai berikut ini:

Tabel 5 Skor Akhir IFAS dan EFAS Aspek Proses

\begin{tabular}{|l|c|l|c|}
\hline \multicolumn{2}{|c|}{ IFAS } & \multicolumn{2}{c|}{ EFAS } \\
\hline Kategori & $\begin{array}{c}\text { Total } \\
\text { Skor }\end{array}$ & \multicolumn{1}{|c|}{ Kategori } & $\begin{array}{l}\text { Total } \\
\text { Skor }\end{array}$ \\
\hline Kekuaran (S) & 3,80 & Peluang (O) & 3,60 \\
\hline Kelemahan (W) & 2,75 & Ancaman $(\mathrm{T})$ & 2,90 \\
\hline Total (S-W) & 1,05 & Total (S-T) & 0,70 \\
\hline
\end{tabular}

Dari hasil matrik IFAS dan EFAS diketahui skor akhir IFAS adalah 1, 05 dan total skor akhir EFAS adalah 0,70. Hasil tersebut kemudian ditunjukkan melalui matrik SWOT di bawah ini:

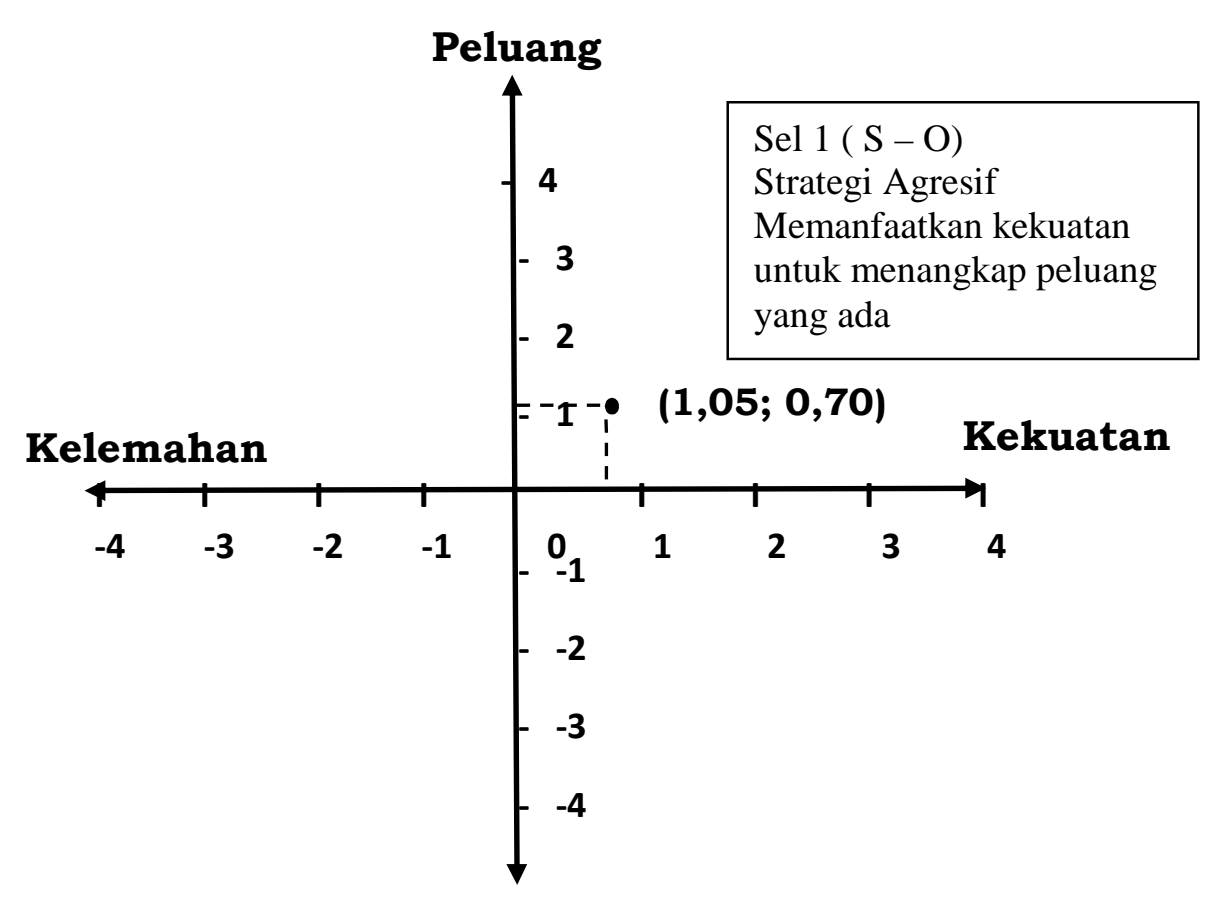

Ancaman

Gambar 4 Matrik SWOT Skor Akhir IFAS dan EFAS Aspek Proses 
Tabel 5 Rencana Strategis Berdasarkan Hasil Analisis SWOT

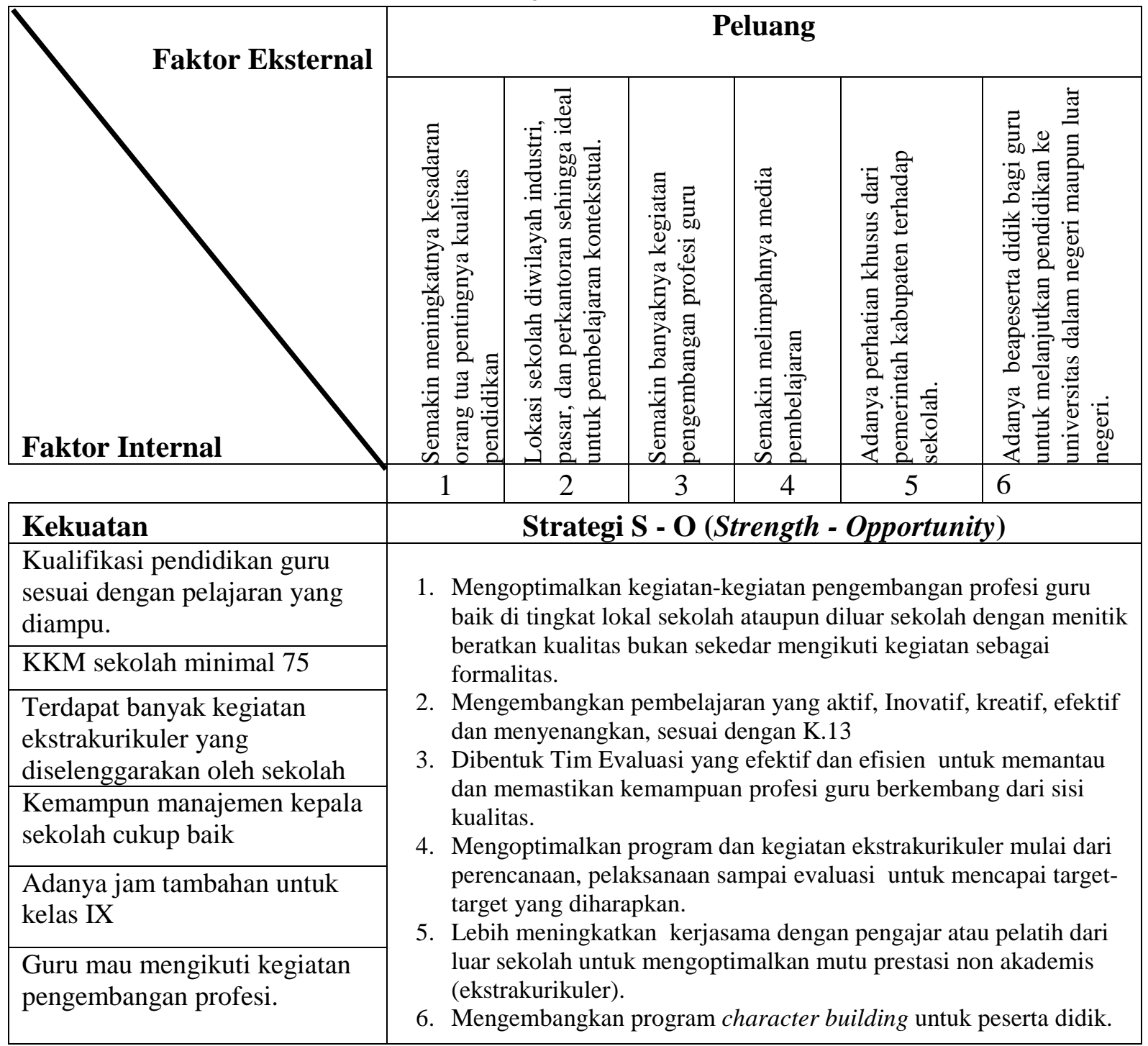

Berdasarkan hasil analisis SWOT tersebut maka rencana strategis yang perlu dibuat sebagai upaya peningkatan mutu sekolah untuk aspek prosesdi SMPN 1 Bawen adalah sebagai berikut: (1) Mengoptimalkan kegiatan-kegiatan pengembangan profesi guru baik di tingkat lokal sekolah ataupun di luar sekolah dengan menitikberatkan kualitas bukan sekedar mengikuti kegiatan sebagai formalitas; (2) Mengembangkan pembelajaran yang aktif, inovatif, kreatif, efektif dan menyenangkan, sesuai dengan K.13; (3) Dibentuk Tim Evaluasi yang efektif dan efisien untuk memantau dan memastikan kemampuan profesi guru berkembang dari sisi kualitas; (4) Mengoptimalkan program dan kegiatan ekstrakurikuler mulai dari perencanaan, pelaksanaan sampai evaluasi untuk mencapai target-target yang diharapkan; (5) Lebih meningkatkan kerjasama dengan pengajar atau pelatih dari luar sekolah untuk mengoptimalkan mutu prestasi non akademis (ekstrakurikuler); (6) Supervisi dan monitoring efektif dan efisien yang dilakukan oleh kepala sekolah.

\section{c. Rencana Strategis Peningkatan Mutu Sekolah Aspek Output}

Setelah mengidentifikasi berbagai faktor kekuatan, kelemahan, peluang dan ancaman untuk aspek output kemudian diberi bobot dan skor maka hasil perhitungan untuk total skor akhir adalah sebagi berikut ini: 
Tabel 6 Skor Akhir IFAS dan EFAS Aspek Output

\begin{tabular}{|l|c|l|c|}
\hline \multicolumn{2}{|c|}{ IFAS } & \multicolumn{2}{c|}{ EFAS } \\
\hline Kategori & $\begin{array}{l}\text { Total } \\
\text { Skor }\end{array}$ & \multicolumn{1}{|c|}{ Kategori } & $\begin{array}{l}\text { Total } \\
\text { Skor }\end{array}$ \\
\hline Kekuatan $(\mathrm{S})$ & 3,70 & Peluang $(\mathrm{O})$ & 4,20 \\
\hline Kelemahan $(\mathrm{W})$ & 3,20 & Ancaman $(\mathrm{T})$ & 3,30 \\
\hline Total $(\mathrm{S}-\mathrm{W})$ & 0,50 & Total $(\mathrm{O}-\mathrm{T})$ & 0,90 \\
\hline
\end{tabular}

Dari hasil matrik IFAS dan EFAS diketahui skor akhir IFAS adalah 0,50 dan total skor akhir EFAS adalah 0,90. Hasil tersebut kemudian ditunjukkan melalui matrik SWOT di bawah ini:

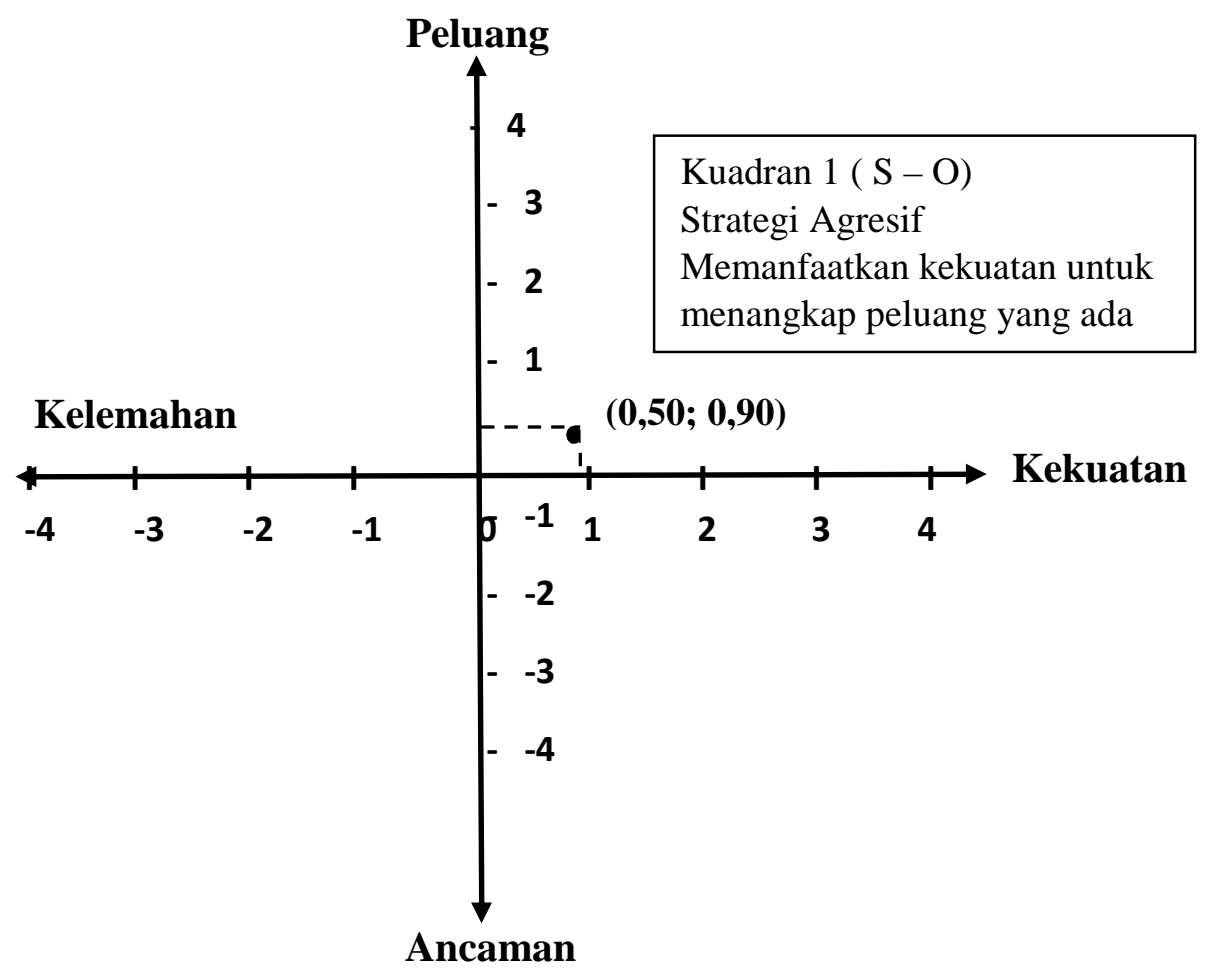

Gambar 5 Matrik SWOT Skor Akhir IFAS dan EFAS Aspek Proses 
Tabel 7 Rencana Strategis Berdasarkan Hasil Analisis SWOT

\begin{tabular}{|c|c|c|c|c|}
\hline \multirow[b]{2}{*}{ Faktor Internal } & \multicolumn{4}{|c|}{ Peluang } \\
\hline & \multirow[t]{2}{*}{ 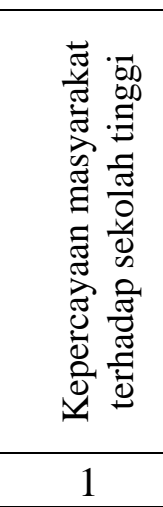 } & 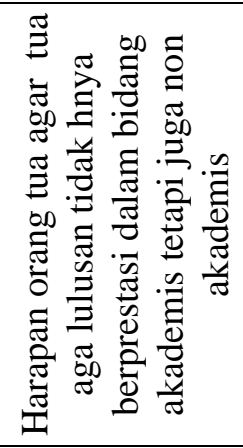 & 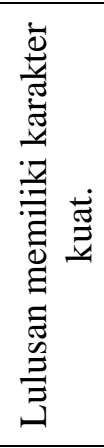 & 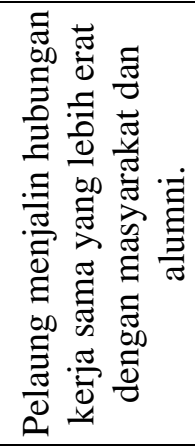 \\
\hline & & 2 & 3 & 4 \\
\hline Kekuatan & \multicolumn{4}{|c|}{ Strategi S - O (Strength - Opportunity) } \\
\hline $\begin{array}{l}\text { Pencapaian prestasi non } \\
\text { akademis kegiatan non } \\
\text { akademis (ekstrakurikuler) } \\
\text { semakin lebih baik. }\end{array}$ & \multirow{4}{*}{\multicolumn{4}{|c|}{$\begin{array}{l}\text { a. Meningkatkan prestasi non-akademis sekolah dengan } \\
\text { seoptimal mungkin. } \\
\text { b. Meningkatkan pembelajaran yang menitikkan pada } \\
\text { pembangunan karakter peserta didik untuk membangun } \\
\text { image positif. } \\
\text { c. Membangun jaringan alumni yang lebih efektif dan } \\
\text { terorganisir. } \\
\text { d. Melakukan terobosan-terobosan untuk percepatan } \\
\text { pencapaian prestasi akademis. }\end{array}$}} \\
\hline $\begin{array}{l}\text { Peringkat sekolah dari tahun ke } \\
\text { tahun mulai meningkat }\end{array}$ & & & & \\
\hline $\begin{array}{l}\text { Prosentase jumlah kelulusan } \\
\text { dari tahun ke tahun meningkat. }\end{array}$ & & & & \\
\hline $\begin{array}{l}\text { Banyak peserta didik diterima di } \\
\text { sekolah favorit. }\end{array}$ & & & & \\
\hline
\end{tabular}

\section{Berdasarkan hasil analisis SWOT}

tersebut maka rencana strategis yang perlu dibuat sebagai upaya peningkatan mutu sekolah untuk aspek output di SMPN 1 Bawen adalah sebagai berikut: Meningkatkan prestasi non-akademis sekolah dengan seoptimal mungkin; (2) Meningkatkan pembelajaran yang menitikberatkan pada pembangunan karakter peserta didik untuk membangun image positif; (3) Membangun jaringan alumni yang lebih efektif dan terorganisir; (4) Melakukan terobosanterobosan untuk percepatan pencapaian prestasi akademis.

Hasil penelitian ini menunjukkan bahwa perencanaan strategis yang disusun secara sistematis berdasarkan analisis SWOT dapat menghasilkan produk renstra yang nantinya diharapkan dapat meningkatkan mutu pendidikan sekolah. Hal itu sesuai dengan pendapat Rangkuti (2009) yang menjelaskan dengan analisis SWOT dapat diketahui Strengths atau hal-hal yang merupakan kelebihan dari organisasi; Weaknesses atau komponen-komponen yang kurang menunjang keberhasilan penyelenggaraan organisasi; Opportunity atau kemungkinan-kemungkinan yang dapat dicapai apabila potensi-potensi yang ada dalam organisasi mampu dikembangkan secara optimal, dan Threats atau kemungkinan yang mungkin terjadi atau pengaruh terhadap kesinambungan dan keberlanjutan organisasi.Melalui analisis SWOT pula dapat diketahui pada posisi kuadran manakah organisasi yang bersangkutan. Dalam penelitian ini, hasil analisis SWOT menunjukkan bahwa baik pada aspek input, proses maupun output semuanya berada pada kuadran S-O yang bermakna bahwa organisasi tersebut kuat dan berpeluang untuk memenangkan persaingan dan rekomendasi strategi yang diberikan adalah progresif, artinya organisasi dalam kondisi prima dan mantap sehingga sangat dimungkinkan untuk terus melakukan 
ekspansi, memperbesar pertumbuhan dan meraih kemajuan secara maksimal.

Hal tersebut senada dengan penelitian yang dilakukan oleh Rozari pada tahun 2011 di SMK St. Petrus Comoro Dili Timor Leste. Juga sesuai dengan hasil penelitian Suharti pada tahun 2013 di SDN 1 Ngadirejo Kecamatan Ngadirejo Kabupaten Temanggung dan hasil penelitian Sumarni pada tahun 2011 di SMP Kristen Satya Wacana Salatiga yang mengungkapkan bahwa untuk menggali kekuatan, kelemahan, peluang dan ancaman suatu organisasi dibutuhkan media analisa yang akurat yaitu analisa SWOT yang selanjutnya digunakan untuk menentukan posisi kuadran. Dari posisi kuadaran masingmasing organisasi selanjutnya diturunkan menjadi rancangan rencana strategis.

Berdasarkan hasil penelitian ini diharapkan penyusunan renstra dapat menjadi titik tolak peningkatan mutu sekolah, mengevaluasi diri dengan analisis SWOT akan semakin memantapkan pijakan perencanaan. Sekolah akan tahu persis dititik mana posisinya berada dengan segala kelebihan, kekurangan, peluang, dan hambatan yang dimiliki, dengan demikian perencanaan akan lebih matang. Sehingga tidak ada istilah, renstra hanya sebagai formalitas pelengkap administrasi. Tidak adalagi menyusun renstra dengan mengcopy renstra sekolah lain, karena tiap sekolah pasti memiliki analisis SWOT yang berbeda. Jika sekolah sadar akan betapa pentingnya sebuah renstra untuk peningkatan mutu sekolah, maka seyogyanya sekolah harus berbenah dan serius dalam menyusun renstra. Seperti pepatahs aat orang gagal merencanakan, maka ia sedang merencanakan kegagalan. Begitu juga saat sekolah gagal menyusun renstra, maka jangan berharap bahwa mutu sekolah akan meningkat.

\section{SIMPULANDANSARAN}

\section{Simpulan}

Berdasarkan hasil analisis dan pembahasan, maka kesimpulan yang dapat diambil adalahhasil analisis SWOT dari aspek input, proses, dan output untuk meningkatkan mutu sekolah menunjukkan posisi SMPN 1 Bawen berada pada kuadran I (SO) yang mendukung pada strategi agresif untuk mendukung pertumbuhan mutu sekolah maka dibuatlah rencana strategis yang menggunakan kekuatan dari lingkungan internal sekolah untuk dapat menangkap peluang dari lingkungan eksternal sekolah.

Rencana strategis yang dibuat untuk meningkatkan mutu dari aspek input adalah: (1) Mengembangkan lingkungan sekolah menuju komunitas belajar yang ideal, yaitu melalui program 7 K (Kebersihan, Ketertiban, Keindahan, Kerindangan, Keamanan, Kenyamanan, dan Kekeluargaan); (2) Membentuk klub-klub prestasi untuk mengembangkan potensi peserta didik, baik dari sisi akademis ataupun non akademis; (3) Mengoptimalkan peran kepala sekolah dalam memberdayakan dan melatih kepemimpinan dan manajerial tenaga pendidik dan tenaga kependidikan; (4) Pengembangan fasilitas sekolah berbasis TIK sebagai sarana untuk belajar peserta didik; (5) Dibentuk Tim Evaluasi program dan kegiatan sekolah secara efektif dan efisien.

Rencana strategis yang dibuat untuk meningkatkan mutu aspek proses: Mengoptimalkan kegiatan-kegiatan pengembangan profesi guru baik di tingkat lokal sekolah ataupun di luar sekolah dengan menitikberatkan kualitas; (2) Mengembangkan pembelajaran yang aktif, inovatif, kreatif, efektif dan menyenangkan; Mengoptimalkan program dan kegiatan ekstrakurikuler mulai dari perencanaan, pelaksanaan sampai evaluasi untuk mencapai target-target yang diharapkan; (4) lebih meningkatkan kerjasama dengan pengajar atau pelatih baik dari luar ataupun dari dalam 
sekolah untuk mengoptimalkan mutu prestasi non akademis (ekstrakurikuler).

Rencana strategis yang dibuat untuk meningkatkan mutu aspek output adalah; (1) Meningkatkan prestasi non-akademis sekolah dengan seoptimal mungkin; (2) Meningkatkan pembelajaran yang menitikberatkan pada pembangunan karakter peserta didik untuk membangun image positif; (3) Membangun jaringan alumni yang lebih efektif dan terorganisir; (4) Melakukan terobosanterobosan untuk percepatan pencapaian prestasi akademis.

\section{Saran}

Berdasarkan hasil penelitian ini, saran yang dapat diberikan adalah:

\section{a. Bagi Kepala Sekolah}

Hasil analisis SWOT posisi SMPN 1 Bawen berada pada posisi kuadran I (SO) yang mendukung pada strategi agresif yang mendukung pertumbuhan dengan memanfaatkan kekuatan yang dimiliki sekolah untuk menangkap peluang yang ada. Hal tersebut perlu keterlibatan semua komponen sekolah dan fihak stakeholder.

Kepala sekolah sebagai manajemen puncak seyogianya bertanggung jawab penuh terhadap pengelolaan dan pemanfaatan semua potensi dan sumber daya sekolah untuk mewujudkan visi misi sekolah, tujuan sekolah dan memenangkan persaingan positif yang ada. Selain itu kepala sekolah sebaiknya lebih mengoptimalkan supervisi, monitoring serta membentuk tim evaluasi untuk memastikan program-progam yang dijalankan dapat berjalan sesuai dengan yang diharapkan dan untuk mengevaluasi kinerja guru.

Selanjutnya diperlukan komitmen yang kuat dari kepala sekolah untuk mengimplementasikan program-program sekolah secara konsisten dan berkesinambungan. Hal tersebut menjadi sangat penting dalam proses peningkatan mutu sekolah baik dalam jangka menengah ataupun jangka panjang.

Selain itu kepala sekolah seyogianya merangkul dan melibatkan semua stakeholder sekolah dalam menyusun rencana strategis agar output atau hasil dari renstra nyata-nyata potret sekolah. Jika hal tersebut dapat terwujud maka renstra sekolah akan mampu menjawab persoalan-persoalan yang muncul.

Penulis memberikan sebuah model ataupun draft rencana strategis peningkatan mutu sekolah berdasarkan analisis SWOT SMPN 1 Bawen yang telah diuji oleh pakar. Sekiranya draft tersebut bermanfaat untuk membantu sekolah dalam menyusun renstra sekolah yang akan habis berlakunya sampai dengan tahun 2015. Sekiranya draft tersebut dapat menjadi bahan masukan untuk sekolah dalam menyusun dan mengembangkan rencana strategis sekolah.

b. Bagi guru dan staf

Para guru dan staf SMP Negeri 1 Bawen seyogianya berkomitmen bersama untuk berperan secara aktif dalam mengoptimalkan pelaksanaan rencana strategis yang sudah disepakati dan disusun bersama dengan tujuan agar sekolah mampu meningkatkan mutu pendidikan. Salah satunya adalah mutu lulusan.

\section{DAFTAR PUSTAKA}

Rangkuti, F. 2009. Analisis SWOT Teknik Membedah Kasus Bisnis, Jakarta: PT Gramedia Pustaka Utama.

Rindaningsih, Ida. (2012). Pengembangan Model Manajemen Stategik Berbasis (Beyond Center and Circle Time) BCCT Pada PAUD. Halaqa Jurnal Fakultas Tarbiyah, Keguruan dan Ilmu Pendidikan UMSIDA. vol. 1. No. 2 Juni 2012. 
Rozari, A.M. 2011. Rencana Strategis Peningkatan Mutu Sekolah Dengan Analisis SWOT di SMK St. Petrus Comoro Dili Timor Leste. Tesis. Salatiga: Program Pasca Sarjana Magister Manajemen Pendidikan

Sugiyono. 2011. Metode Penelitian Kuantitatif Kualitatif dan $R \quad \& \quad D$, Bandung: Alfabeta.

Suharti, R. 2013. Alternatif Strategi Peningkatan Mutu Sekolah Berdasarkan Analisis SWOT di SDN 1 Ngadirejo Kecamatan Ngadirejo Kabupaten Temanggung. Tesis. Salatiga: Program Pasca Sarjana Magister Manajemen Pendidikan.

Sumarni, N. 2011. Strategi Peningkatan Mutu Sekolah Berdasarkan Analisa SWOT Pada SMP Kristen Satya Wacana Salatiga. Tesis, Salatiga: Program Pasca Sarjana Magister Manajemen Pendidikan.

Tjiptono, F dan Diana, A, 2003. Total Quality Management. Andi Offset, Yogyakarta

Usman, U. 2002. Menjadi Guru Profesional. Bandung: Remaja Rosdakarya. 